\title{
A Simple and Fast Method to Synthesize Cubic Iridium Nanoparticles with Clean Surface Free from Surfactants
}

\author{
Rongrong Zhang ${ }^{\dagger}$, Xuan Liu ${ }^{\dagger}$, Litong Shi, Xin Jin, Yanchao Dong, Kang Li, Xihui Zhao, Qun Li * \\ and Yujia Deng * \\ School of Chemistry and Chemical Engineering, Qingdao University, Qingdao 266071, China; \\ zhangrr0809@163.com (R.Z.); liuxuan2795@163.com (X.L.); 15666191885@163.com (L.S.); \\ 17863966345@163.com (X.J.); 17805420783@163.com (Y.D.); lk17866634806@163.com (K.L.); \\ zhaoxihui@qdu.edu.cn (X.Z.) \\ * Correspondence: qunli501@163.com (Q.L.); dengyujia@qdu.edu.cn (Y.D.) \\ + These authors contributed equally to this work.
}

Received: 16 December 2018; Accepted: 6 January 2019; Published: 8 January 2019

\begin{abstract}
Cubic Iridium nanoparticles without any surfactants on the surface have been synthesized successfully in this work. The process of synthesis was quite simple by just injecting one drop of $400 \mu \mathrm{L}$ solution containing Iridium precursor onto $\mathrm{Cu}$ foil $(1 \mathrm{~cm} \times 1 \mathrm{~cm})$, and through galvanic reaction between the Ir precursor and $\mathrm{Cu}$ foil, the cubic Iridium nanoparticle could be obtained quite quickly $(<30 \mathrm{~s})$. The $\mathrm{Cu}$ foil played the roles of both reducing agent and substrate. This method could also be employed to synthesize cubic nanoparticles of other Pt-group metals such as Rh. By employing this method, cubic metal nanoparticles with surfactant-free surfaces could be produced economically and efficiently, and as a result, a realistic relationship between structure and catalytic activity could be established.
\end{abstract}

Keywords: Iridium nanoparticles; cubic; $\mathrm{Cu}$ foil; free from surfactants; galvanic reaction

\section{Introduction}

In recent decades, nanoparticles have boosted the development of catalysis, due to their high surface-area-to-volume ratio resulting in increased exposure of the catalytic active sites, and reduced usage of noble metals [1-3]. Nanocatalysts produced from Pt-group metals have been widely used in energy fields such as fuel cells [4,5]. Fundamental studies indicated that the surface structure could have significant effects on their catalytic performances. For example, $\mathrm{Pt}(110)$ could have higher catalytic activity than that of $\mathrm{Pt}(111)$ towards oxygen reduction reaction in $\mathrm{HClO}_{4}$ solution and similar phenomena have been also found in Ir catalytic processes [1,6-8]. To enhance the catalytic performances of Pt-group metals for certain reaction, nanoparticles enclosed with specified surface structure are preferred, and this can be achieved when shape-controlled synthesis of the nanomaterials is used. Recent decades have witnessed the quick development of shape-controlled synthesis of nanomaterials. Shape-controlled synthesis of Pt-group metal nanocrystals (NCs), such as Pt, Pd, were of great success and the synthesized nanomaterials have shown excellent catalytic activity $[4,9,10]$. Among Pt-group metals, Ir was supposed to be an ideal catalyst candidate for oxygen evolution reaction (OER) due to its activity and stability $[8,11,12]$. However, the realization of shape-controlled synthesis of pure Ir nanocrystals remained a significant challenge. Xia employed cubic Pd nanocrystals as seed and synthesized cubic Pd-Ir core-shell nanoparticles, but the process was a little complex and the conditions were critical at high temperature [13]. In addition, most reported synthesis processes of shaped nanoparticles of Pt-group metals employed surfactants such as PVP, CTAB, 
etc. $[10,14]$. These surfactants could adsorb strongly on the surface of the nanoparticles thus affecting its catalytic activity. It is widely accepted that a better understanding of the correlation between surface structure and catalytic performance can be obtained when the surface of the metal is free of adsorbed contaminants [15]. In this respect, the development of an effective method to synthesize nanoparticles without surfactants on the surfaces became an extremely important prerequisite for subsequently evaluating their catalytic performances. So far, despite much effort, there has been limited success in finding efficient methods for the removal of adsorbed contaminants from the surface of nanocatalysts [16-19]. Since it is difficult to remove the surfacants after they are adsorbed on the surface of nanocatalysts as synthesized, a simple strategy would be to avoid introducing them at the stage of synthesis. Although shaped Pt, Pd nanoparticles with clean surfaces free from surfactants have been acquired by this strategy [20-22], no shaped Iridium nanoparticles have been similarly produced. Therefore, shape-controlled synthesis of Ir nanoparticles with clean surfaces could be quite appealing. Hitherto, Kibler et al. employed square-wave potential procedure and successfully electrodeposited Ir nanoparticles on a glassy carbon electrode. Although the nanoparticles were free from surfactants, they were nanospheres enclosed with poly-crystal facets [23]. In earlier work, Dai et al. reported that $\mathrm{Pt}$ nanocubes could be directly deposited onto $\mathrm{Cu}$ foil by reacting appropriate aqueous solutions of $\mathrm{K}_{2} \mathrm{PtCl}_{4}$ with $\mathrm{Cu}$ foil via a galvanic displacement reaction for given reaction times [22]. The method has been successfully used to synthesize Pt and Au cubic nanoparticles without surfactants. The finding from their study suggests that it is possible to synthesize cubic Iridium nanoparticles with clean surfaces. Herein, we report a simple method for the synthesis of surfactant-free cubic Ir nanoparticles that can be extended to the production of cubic nanoparticles of other noble metals, such as rhodium.

\section{Experimental}

$\mathrm{IrCl}_{3}$ (GR) and $\mathrm{Na}_{3} \mathrm{RhCl}_{6}$ (GR) were purchased from Rhawn and Alfa Aesar, respectively. Before reaction, $\mathrm{Cu}$ foil $(1 \mathrm{~cm} \times 1 \mathrm{~cm})$ was pretreated by putting it in sulfuric acid for $5 \mathrm{~s}$ to clean the surface and then was washed by Milli-Q water $(18.2 \mathrm{M} \Omega \mathrm{cm})$ to remove the acid. All the solution used was prepared with Milli-Q water. In a typical process of synthesis, Ir nanoparticles were produced by injecting a drop of $400 \mu \mathrm{L}$ of $2 \mathrm{mM} \mathrm{IrCl}{ }_{3}+10 \mathrm{mM} \mathrm{CuCl}_{2}$ aqueous solution onto the pretreated $\mathrm{Cu}$ foils by pipette at room temperature for a certain period of time, followed by thoroughly rinsing with Milli-Q water. For the synthesis of Rh nanoparticles, the process was similar but with a drop of $400 \mu \mathrm{L}$ of $2 \mathrm{mM} \mathrm{Na}_{3} \mathrm{RhCl}_{6}+10 \mathrm{mM} \mathrm{CuCl}_{2}$ aqueous solution. For the oxidation of $3,3^{\prime}, 5,5^{\prime}$-tetramethylbenzidine (TMB) by $\mathrm{H}_{2} \mathrm{O}_{2}$, the reactions were carried out in $5 \mathrm{~mL}$ potassium biphthalate buffer solution ( $\mathrm{pH} 4.0$ ), containing $2 \mathrm{M} \mathrm{H}_{2} \mathrm{O}_{2}$ and $0.8 \mathrm{mM}$ TMB as the substrates and the $\mathrm{Cu}$ foil with Iridium nanoparticles was put in the solution as catalysts. The morphology and structure of the nanoparticles were characterized by scanning electron microscopy (SEM, Hitachi S-4800), transmission electron microscopy (TEM, JEM-2100 at $200 \mathrm{kV}$ ). An energy-dispersive X-ray spectroscopic (EDS) detecting unit was used for the element analysis. UV-vis spectra were obtained on a Shimadzu UV3150. X-ray diffraction (XRD) measurements were performed on X-ray diffractometer (D/MAX-RB) using $\mathrm{CuK} \alpha$ radiation $(\lambda=0.15418 \mathrm{~nm})$.

\section{Results and Discussion}

Figure 1 shows the SEM image of Ir nanoparticles obtained by galvanic displacement reaction between $\mathrm{Cu}$ foils and aqueous $\mathrm{IrCl}_{3}$ solutions for a constant deposition time of $60 \mathrm{~min}$. Figure 1a shows the schematic illustration of metal nanoparticle deposited on $\mathrm{Cu}$ foil through galvanic process. A drop of $400 \mu \mathrm{L}$ of $2 \mathrm{mM} \mathrm{IrCl}{ }_{3}+10 \mathrm{mM} \mathrm{CuCl}_{2}$ aqueous solution was injected onto the pretreated $\mathrm{Cu}$ foils by pipette and after reaction for $60 \mathrm{~min}$, the Ir nanoparticles formed on the surface. Figure $1 \mathrm{~b}$ displays a low-magnification SEM image of the as-prepared Ir nanoparticles. It has found that the Ir NCs with cubic shape were the dominant products with a typical yield of nearly $100 \%$. The nanoparticles distributed evenly on the surface of $\mathrm{Cu}$ foil. The high-magnification SEM image in the inset in Figure 1a illustrates clearly the perfect cubic shape of the Ir NCs, with sharply faceted edges. Figure 1c shows 
the size distribution of the Ir nanoparticles as synthesized. The size distribution of nanoparticles was determined by measuring the edge of each nanoparticle. As shown in Figure 1c, the size of the cubic Ir NCs varies from 120 to $200 \mathrm{~nm}$ with an average of $157.7 \mathrm{~nm}$, relative standard deviation $($ RSD) $=$ $7.7 \%$. Figure $1 \mathrm{~d}$ shows the EDS of the sample and it indicated that the nanoparticles grown on the $\mathrm{Cu}$ foil were Iridium. These results indicate that the cubic Iridium nanoparticles were successfully synthesized by the simple galvanic reaction.

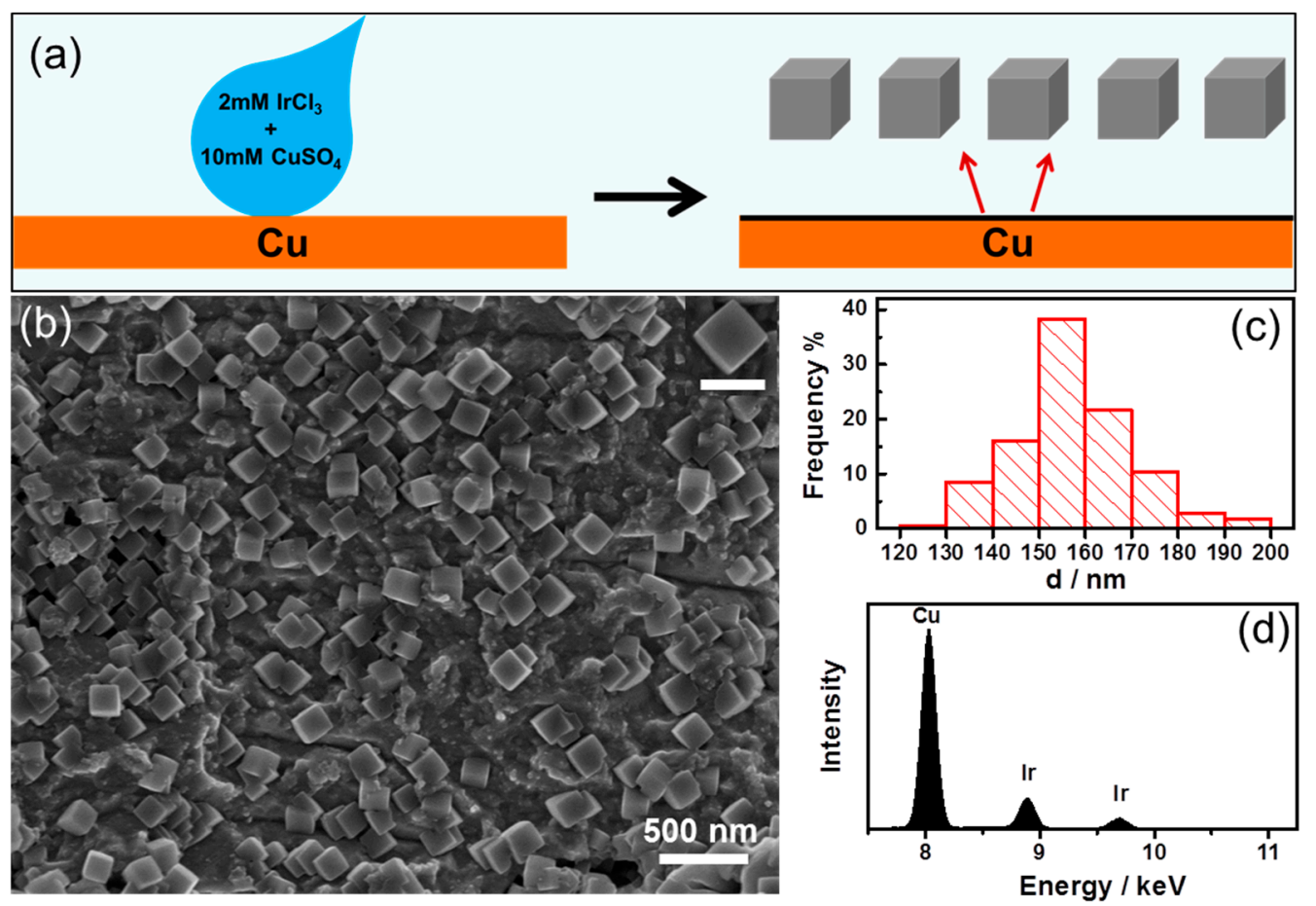

Figure 1. (a) Schematic illustration of metal nanoparticle deposition on Cu foil. (b) Overview SEM image of the Iridium nanoparticles and the inset was high magnification, and the scale bar in it is $200 \mathrm{~nm}$. (c) Size distribution of the synthesized Iridium nanoparticles. (d) EDS of the Iridium nanoparticles as synthesized.

Figure 2a shows the TEM image of a single Ir nanoparticle alone [001], clearly demonstrating the cubic shape. This was fully consistent with the SEM observations (Figure 1b). Figure 2b shows the selected-area electron diffraction (SAED) pattern of the Iridium nanoparticle and the fourfold symmetry of the SAED pattern confirmed that the cubic Ir NC was a single crystalline. The angle between $\mathrm{OA}$ and $\mathrm{OB}$ was $45^{\circ}$, and the distance ratio between $\mathrm{OB}$ and $\mathrm{OA}$ is 1.414 , the results indicated that the formed cubic Ir nanoparticles were enclosed by (100) facets. Figure 2c shows the XRD of the nanoparticles as shown in Figure 1 and the peak at $47.3^{\circ}$ confirmed the existence of the (200) diffraction peak for cubic Ir (JCPDS 06-0598) [24]. The results further indicated the cubic Iridium nanoparticles were enclosed with (100) facets.

It was reported that Ir nanoparticles could catalyze the oxidation of 3,3',5,5'-tetramethylbenzidine (TMB) by $\mathrm{H}_{2} \mathrm{O}_{2}$ and yielding a blue-colored product with a maximum absorbance at $653 \mathrm{~nm}$ [13]. We employed this method to further characterize the as-synthesized Ir cubes. As shown in Figure 3, In the presence of the cubic Ir nanoparticles, the oxidation of TMB by $\mathrm{H}_{2} \mathrm{O}_{2}$ could be achieved and yielding a blue-colored product with a maximum absorbance at $653 \mathrm{~nm}$ and the color change was quite obvious from colorless to blue as the catalysis reaction proceeded, which was consistent well with that reported in literature. This result further confirmed that the nanoparticles were Iridium. 

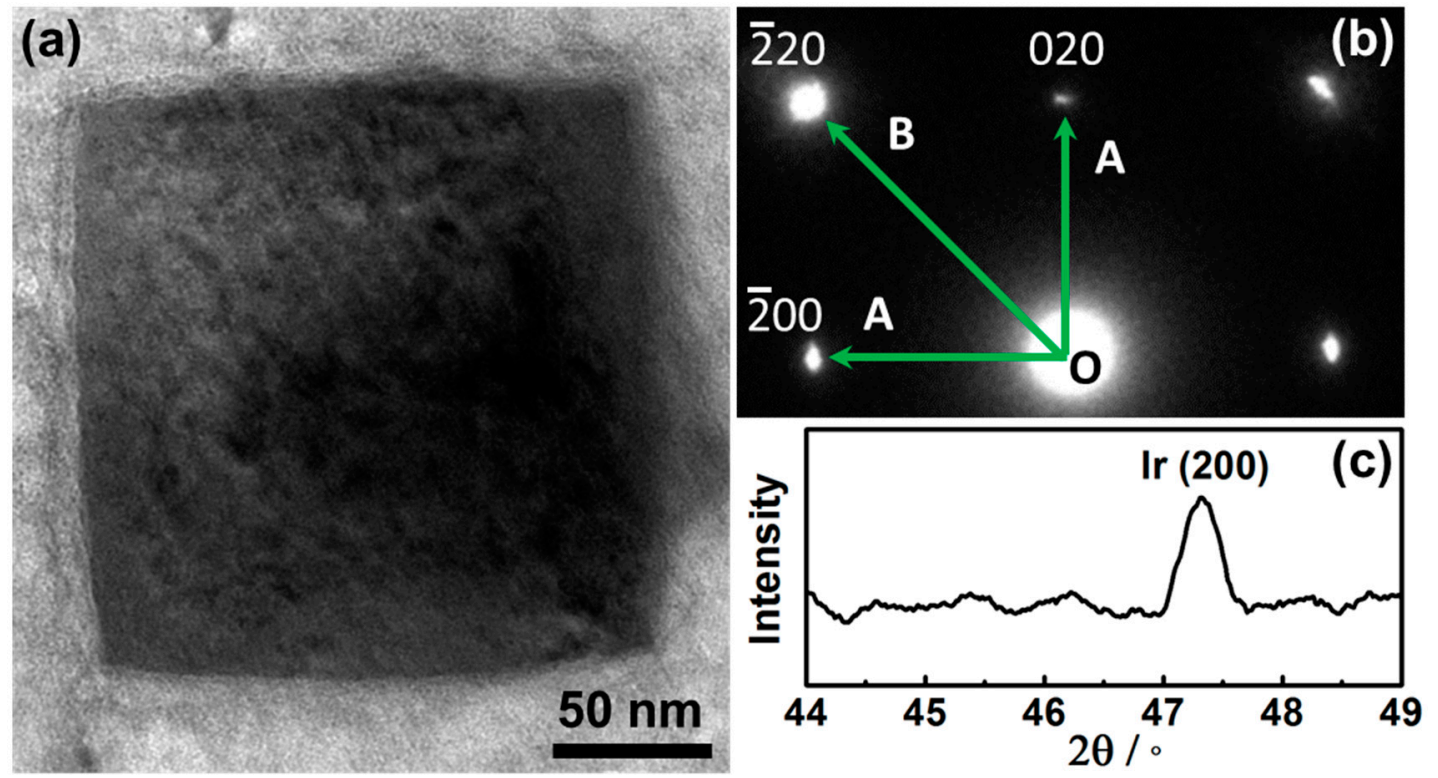

Figure 2. (a) TEM of a typical Ir nanoparticle. (b) SAED of the nanoparticle. (c) XRD of the nanoparticles as synthesized on $\mathrm{Cu}$ foil.

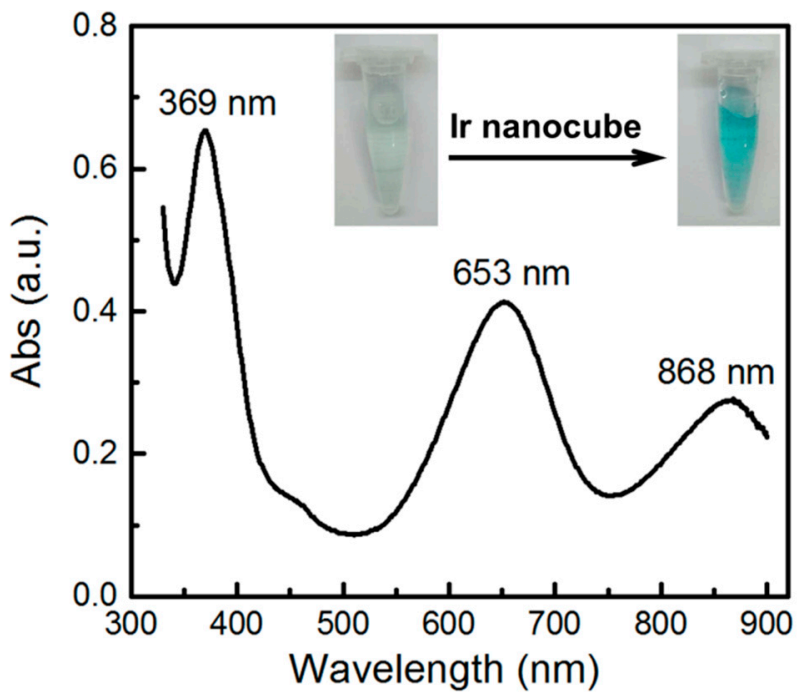

Figure 3. UV-vis spectrum characterization of $\mathrm{TMB}$ oxidation by $\mathrm{H}_{2} \mathrm{O}_{2}$ catalyzed by cubic Ir nanoparticles.

When we injected the drop of solution onto the $\mathrm{Cu}$ foil, we found that the surface of the $\mathrm{Cu}$ foil turned black immediately. This made us interested to check how fast the cubic Ir nanoparticles could form. To investigate this, we conducted the experiment as before but made the time much shorter until it was only $30 \mathrm{~s}$. In addition, the results are shown in Figure 4. In Figure 4a, it can be seen that on the surface of the $\mathrm{Cu}$ plate, the nanoparticles were distributed evenly on the surface and most of them were cubic. In Figure $4 \mathrm{~b}$, it can be seen that most of the size ranged from 80 to $150 \mathrm{~nm}$, and the average size was $114.2 \mathrm{~nm}$, and RSD was $9.5 \%$. By checking carefully, we found there were several nanoparticles much smaller than the average size, but these nanoparticles could be seen clearly with well cubic shape. The results demonstrated that the galvanic displacement reaction could be quite fast, and the cubic shape should be achieved quickly $(<30 \mathrm{~s})$ and grew to a large size soon. Since only one drop of $400 \mu \mathrm{L}$ of solution containing Iridium precursor was used to react with the $\mathrm{Cu}$ foil and the galvanic reaction was fast, the nanoparticles did not grow so much from $30 \mathrm{~s}$ to $60 \mathrm{~min}$ as the average size changed from 114.2 to $157.7 \mathrm{~nm}$. This meant that we could employ this method to obtain cubic 
Iridium nanoparticle in short time with limited reactants and this could facilitate to produce them as catalysts at large scale.
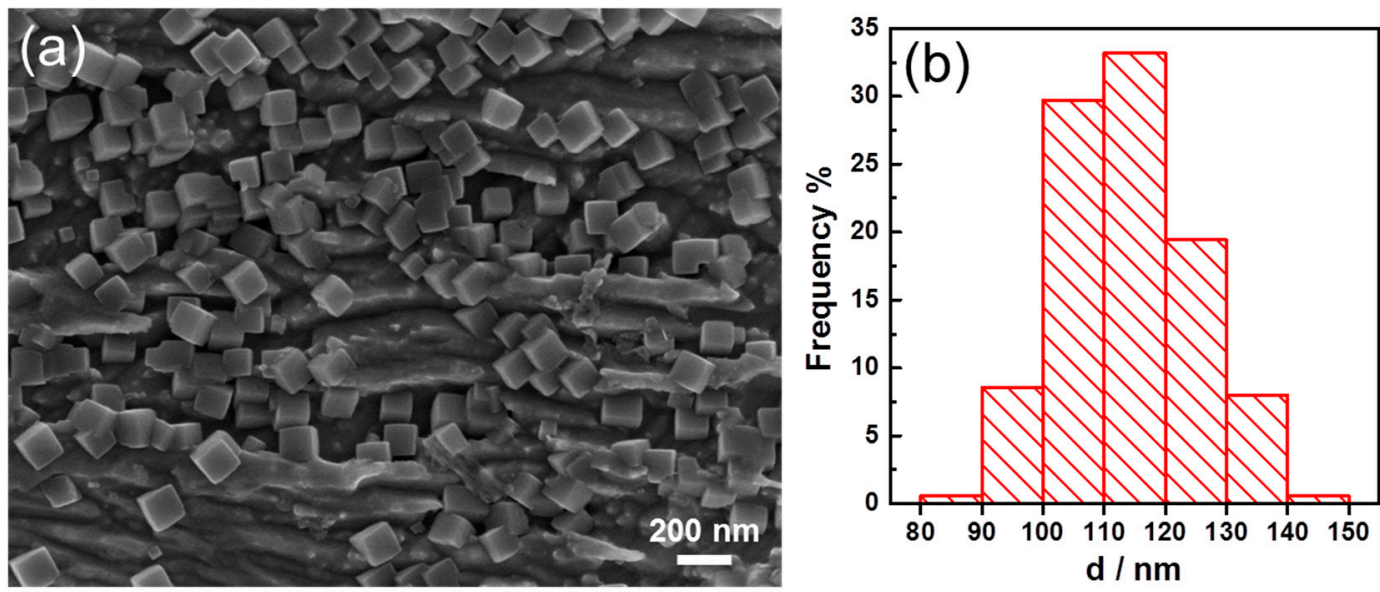

Figure 4. (a) SEM of the Iridium nanoparticles synthesized for $30 \mathrm{~s}$. (b) Size distribution of the synthesized Iridium nanoparticles.

Compared with the method described by Dai to synthesize cubic Pt nanoparticles, we have simplified the synthesis process with only one drop of precursor solution. Thus, each drop of the solution could be a reaction spot. This made the synthesis more economic and efficient. This simple method could be expanded to synthesize other cubic nanoparticles of Pt-group metals such as Rh. Figure 5 shows the Rh nanoparticles synthesized by the same method but with a drop of solution containing Rh precursor for $3 \mathrm{~min}$. In Figure 5a, most of the nanoparticles were cubic shape, and though some of the nanoparticles grew together, their cubic profiles were clear. Figure $5 b$ shows size distribution of the Rh nanoparticles as synthesized. It shows the size of nanoparticles ranged from 130 to $210 \mathrm{~nm}$ and the average size was $163.1 \mathrm{~nm}$ and RSD was $9.6 \%$.
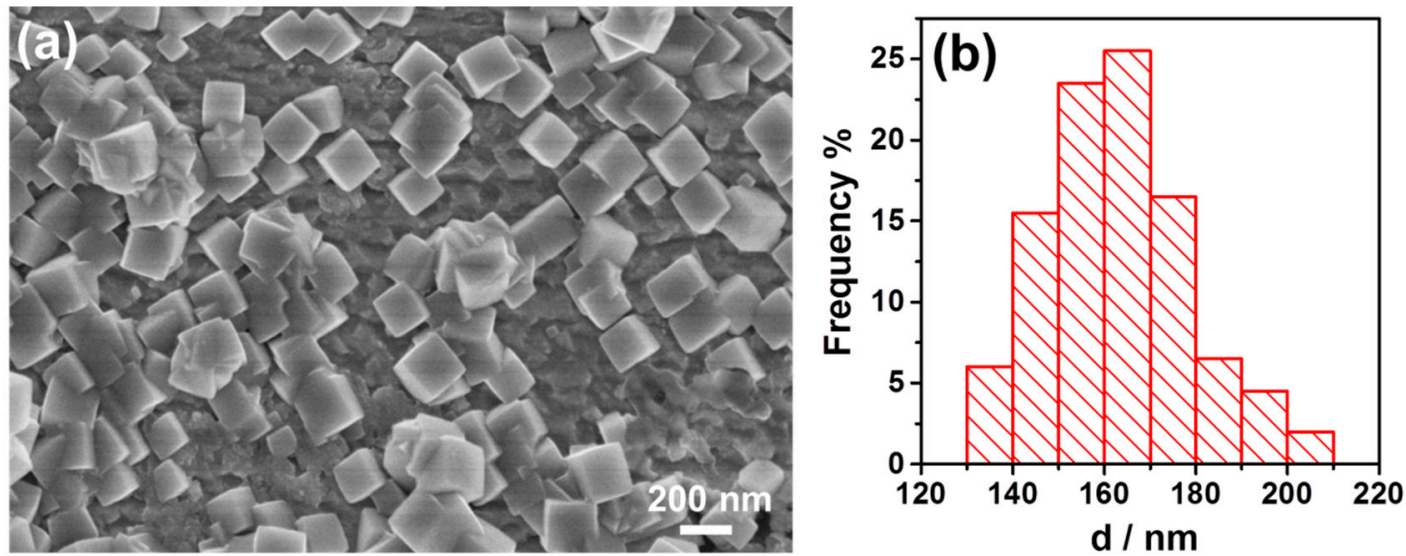

Figure 5. (a) SEM of the Rh nanoparticles synthesized for 3min. (b) Size distribution of the Rh nanoparticles as synthesized.

\section{Conclusions}

In conclusion, we have developed a simple method to synthesize cubic Iridium nanoparticles with clean surfaces through galvanic reaction. For each synthesis, only one drop of solution containing precursor was employed, which made the synthesis quite economic and efficient. Since the galvanic reaction could be quite fast and the cubic nanoparticles could form in a short time $(<30 \mathrm{~s})$ with only one drop of $400 \mu \mathrm{L}$ solution injecting onto the $\mathrm{Cu}$ foil, it made possible the synthesis of cubic Iridium nanoparticles as catalysts at a large scale. This method could also be employed to synthesize other 
cubic nanoparticles with clean surfaces such as $\mathrm{Rh}$. In the future, we will introduce supports such as graphene to broaden the application of the nanoparticles as synthesized, since the $\mathrm{Cu}$ support was not so electrochemically stable and could be corroded at a critical condition, which might be improved by introducing stable supports such as carbon materials.

Author Contributions: Conceptualization, Y.D.; Data curation, R.Z., X.L., L.S., X.J., Y.D., K.L., X.Z., Q.L. and Y.D.; Formal analysis, R.Z., X.L., L.S., X.J., Y.D., K.L., X.Z., Q.L. and Y.D.; Funding acquisition, Y.D.; Investigation, R.Z., X.L., Q.L. and Y.D.; Methodology, Y.D.; Project administration, Y.D.; Writing-original draft, Y.D.; Writing一review \& editing, Q.L. and Y.D.

Funding: This work was supported by the National Natural Science Foundation of China (21703114), Natural Science Foundation of Shandong Province (ZR2016BP03), Key Research Project of Shandong Province (2018GGX102011) and Foundation of Qingdao University (41117010117).

Conflicts of Interest: The authors declare no competing financial interest.

\section{References}

1. Seh, Z.W.; Kibsgaard, J.; Dickens, C.F.; Chorkendorff, I.B.; Norskov, J.K.; Jaramillo, T.F. Combining theory and experiment in electrocatalysis: Insights into materials design. Science 2017, 355, 146. [CrossRef]

2. Reier, T.; Oezaslan, M.; Strasser, P. Electrocatalytic Oxygen Evolution Reaction (OER) on Ru, Ir, and Pt Catalysts: A Comparative Study of Nanoparticles and Bulk Materials. ACS Catal. 2012, 2, 1765-1772. [CrossRef]

3. Nesselberger, M.; Ashton, S.; Meier, J.C.; Katsounaros, I.; Mayrhofer, K.J.J.; Arenz, M. The Particle Size Effect on the Oxygen Reduction Reaction Activity of Pt Catalysts: Influence of Electrolyte and Relation to Single Crystal Models. J. Am. Chem. Soc. 2011, 133, 17428-17433. [CrossRef] [PubMed]

4. Shao, M.H.; Chang, Q.W.; Dodelet, J.P.; Chenitz, R. Recent Advances in Electrocatalysts for Oxygen Reduction Reaction. Chem. Rev. 2016, 116, 3594-3657. [CrossRef] [PubMed]

5. Gasteiger, H.A.; Kocha, S.S.; Sompalli, B.; Wagner, F.T. Activity benchmarks and requirements for Pt, Pt-alloy, and non-Pt oxygen reduction catalysts for PEMFCs. Appl. Catal. B Environ. 2005, 56, 9-35. [CrossRef]

6. Kuzume, A.; Herrero, E.; Feliu, J.M. Oxygen reduction on stepped platinum surfaces in acidic media. J. Electroanal. Chem. 2007, 599, 333-343. [CrossRef]

7. Gomez-Marin, A.M.; Feliu, J.M. Oxygen reduction on nanostructured platinum surfaces in acidic media: Promoting effect of surface steps and ideal response of Pt(111). Catal. Today 2015, 244, 172-176. [CrossRef]

8. Ozer, E.; Spori, C.; Reier, T.; Strasser, P. Iridium(111), Iridium(110), and Ruthenium(0001) Single Crystals as Model Catalysts for the Oxygen Evolution Reaction: Insights into the Electrochemical Oxide Formation and Electrocatalytic Activity. Chemcatchem 2017, 9, 597-603. [CrossRef]

9. Zhou, Z.Y.; Tian, N.; Li, J.T.; Broadwell, I.; Sun, S.G. Nanomaterials of high surface energy with exceptional properties in catalysis and energy storage. Chem. Soc. Rev. 2011, 40, 4167-4185. [CrossRef]

10. Peng, Z.M.; Yang, H. Designer platinum nanoparticles: Control of shape, composition in alloy, nanostructure and electrocatalytic property. Nano Today 2009, 4, 143-164. [CrossRef]

11. Pi, Y.C.; Zhang, N.; Guo, S.J.; Guo, J.; Huang, X.Q. Ultrathin Laminar Ir Superstructure as Highly Efficient Oxygen Evolution Electrocatalyst in Broad pH Range. Nano Lett. 2016, 16, 4424-4430. [CrossRef]

12. Antolini, E. Iridium As Catalyst and Cocatalyst for Oxygen Evolution/Reduction in Acidic Polymer Electrolyte Membrane Electrolyzers and Fuel Cells. ACS Catal. 2014, 4, 1426-1440. [CrossRef]

13. Xia, X.H.; Zhang, J.T.; Lu, N.; Kim, M.J.; Ghale, K.; Xu, Y.; McKenzie, E.; Liu, J.B.; Yet, H.H. Pd-Ir Core-Shell Nanocubes: A Type of Highly Efficient and Versatile Peroxidase Mimic. ACS Nano 2015, 9, 9994-10004. [CrossRef]

14. Xia, Y.N.; Xiong, Y.J.; Lim, B.; Skrabalak, S.E. Shape-Controlled Synthesis of Metal Nanocrystals: Simple Chemistry Meets Complex Physics? Angew. Chem. Int. Ed. 2009, 48, 60-103. [CrossRef] [PubMed]

15. Montiel, M.A.; Vidal-Iglesias, F.J.; Montiel, V.; Solla-Gullon, J. Electrocatalysis on shape-controlled metal nanoparticles: Progress in surface cleaning methodologies. Curr. Opin. Electrochem. 2017, 1, 34-39. [CrossRef]

16. Aliaga, C.; Park, J.Y.; Yamada, Y.; Lee, H.S.; Tsung, C.K.; Yang, P.D.; Somorjai, G.A. Sum Frequency Generation and Catalytic Reaction Studies of the Removal of Organic Capping Agents from Pt Nanoparticles by UV-Ozone Treatment. J. Phys. Chem. C 2009, 113, 6150-6155. [CrossRef] 
17. Naresh, N.; Wasim, F.G.S.; Ladewig, B.P.; Neergat, M. Removal of surfactant and capping agent from Pd nanocubes (Pd-NCs) using tert-butylamine: its effect on electrochemical characteristics. J. Mater. Chem. A 2013, 1, 8553-8559. [CrossRef]

18. Nalajala, N.; Saleha, W.F.G.; Ladewig, B.P.; Neergat, M. Sodium borohydride treatment: a simple and effective process for the removal of stabilizer and capping agents from shape-controlled palladium nanoparticles. Chem. Commun. 2014, 50, 9365-9368. [CrossRef]

19. Yang, H.Z.; Tang, Y.G.; Zou, S.Z. Electrochemical removal of surfactants from Pt nanocubes. Electrochem. Commun. 2014, 38, 134-137. [CrossRef]

20. Tian, N.; Zhou, Z.Y.; Sun, S.G.; Ding, Y.; Wang, Z.L. Synthesis of tetrahexahedral platinum nanocrystals with high-index facets and high electro-oxidation activity. Science 2007, 316, 732-735. [CrossRef]

21. Tian, N.; Zhou, Z.Y.; Yu, N.F.; Wang, L.Y.; Sun, S.G. Direct electrodeposition of tetrahexahedral Pd nanocrystals with high-index facets and high catalytic activity for ethanol electrooxidation. J. Am. Chem. Soc. 2010, 132, 7580-7581. [CrossRef] [PubMed]

22. Qu, L.T.; Dai, L.M.; Osawa, E. Shape/size-control led syntheses of metal nanoparticles for site-selective modification of carbon nanotubes. J. Am. Chem. Soc. 2006, 128, 5523-5532. [CrossRef]

23. Sheasha, Y.; Soliman, K.A.; Sun, S.G.; Jacob, T.; Kibler, L.A. Electrochemical Fabrication of Well-Defined Spherical Iridium Nanoparticles and Electrocatalytic Activity towards Carbon Monoxide Adlayer Oxidation. Electrocatalysis 2015, 6, 365-372. [CrossRef]

24. Kim, H.W.; Shim, S.H.; Myung, J.H.; Lee, C. Annealing effects on the structural properties of $\mathrm{IrO}_{2}$ thin films. Vacuum 2008, 82, 1400-1403. [CrossRef]

(C) 2019 by the authors. Licensee MDPI, Basel, Switzerland. This article is an open access article distributed under the terms and conditions of the Creative Commons Attribution (CC BY) license (http:/ / creativecommons.org/licenses/by/4.0/). 